\title{
EL PARQUE AGRARIO DEL BAIX LLOBREGAT: UN PAISAJE CULTURAL
}

Josep Montasell

\section{RESUMEN}

La experiencia del Parque Agrario del Llobregat como espacio agrario inmerso en un contexto altamente urbanizado, rodeado de infraestructuras y sometido a la presión de los entornos urbanos es una excusa perfecta para evaluar un proceso que intenta poner en el mismo camino las necesidades de los agricultores y el sistema productivo, con la visión de paisaje necesitado de protección que se aborda desde la ciudad. La combinación de ambas visiones se verifica a partir de entender el problema como un paisaje cultural.

\section{ABSTRACT}

The experience of the Llobregat Agricultural Park as an agricultural area immersed in a highly urbanized context, surrounded by infrastructural elements and under a high pressure of urban environments is a perfect excuse to assess a process that tries to balance farmers and production system needs with a urban vision of landscape that needs protection. The combination of both perspectives is analised understanding the area as a cultural landscape. 


\section{EL PARQUE AGRARIO Y LOS PAISAJES CULTURALES}

En el Parque Agrario del Baix Llobregat confluyen claramente dos conceptos, paisaje y cultura. Son conceptos ligados a procesos históricos, donde los principales actores han sido, y siguen siendo, los agricultores, que a través de su trabajo constante han ido transformando la realidad. El conocimiento adquirido mediante la transmisión oral de padres a hijos y a través de técnicos de la administración pública, de casas comerciales, o contratados por los propios agricultores a través de las cooperativas o de las Agrupaciones de Defensa Vegetal (ADV), supusieron, en la mayoría de los casos, un aprendizaje basado más en la información que en la formación. ${ }^{1}$

De este modo se incorporó una cultura de intensificación de la producción agraria y uso de pesticidas y abonos que, llevados al límite provocan situaciones de agresión a los recursos naturales como el suelo y el agua, con importantes transformaciones en el paisaje.

De un tiempo a esta parte las administraciones, los técnicos y los agricultores estamos comprendiendo que es necesario que las cosas evolucionen, convenciéndonos de que debemos abandonar determinados hábitos que pueden ser negativos para las personas o los recursos naturales. Debemos buscar métodos alternativos y eficaces basados en la enseñanza de procesos y principios rectores que hagan posible llevar a cabo un manejo agronómico apropiado a las producciones, de acuerdo con las características agroecológicas, económicas y culturales del espacio productivo y de su empresa agraria.

Se trata no tanto de aportar conocimientos basados en la información, sino de apoyarse en un aprendizaje permanente que implique modificaciones en los conocimientos, habilidades y valores, para incorporar una nueva conducta agronómica que defina una agricultura más ligada al ecosistema agrario y

\footnotetext{
1 Recordemos el asesoramiento del Servicio de Extensión Agraria de los años 70 y 80 o las conferencias y cursos de las Oficinas Comarcales del Departamento de Agricultura Ganadería y Pesca de los años 90.
}

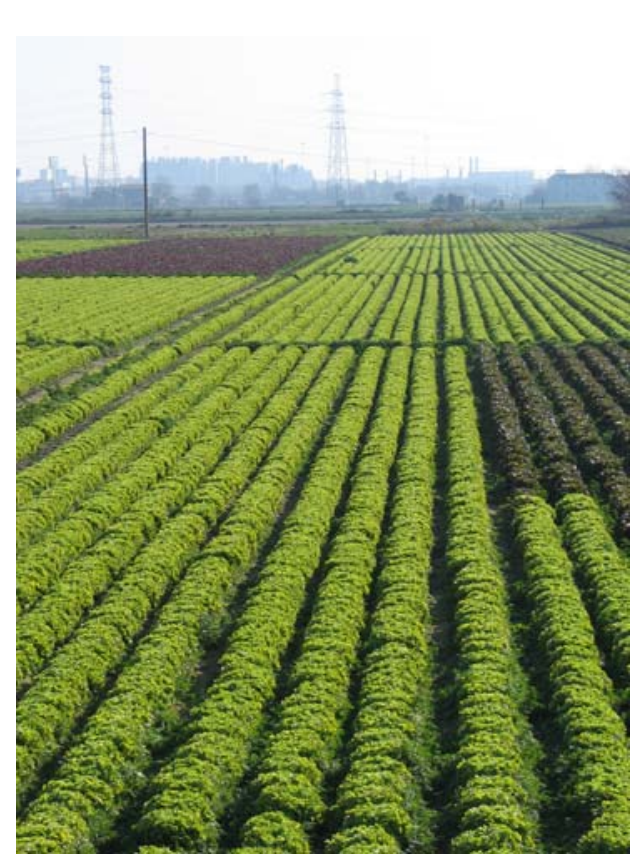

Cultivos en el Delta del río Llobregat 
donde se establezcan relaciones complejas e inter-independientes. Que los agricultores sean depositarios de información agronómica o portadores de conocimientos es sensiblemente diferente a la hora de su relación con la tierra, elemento fundamental para poder desarrollar su actividad profesional y en consecuencia, el resultado final del paisaje.

El paisaje no es otra cosa que el aspecto de los lugares, es la primera impresión visual, la distancia respecto a la visión cotidiana del espacio. Para el agricultor no es algo externo, sino que tiene un fuerte vínculo con su territorio y va más allá de una percepción, precisamente porque es más simbiótica. Los agricultores nunca hablan de paisaje ya que éste a menudo va asociado a reivindicación y presión exterior sobre ellos en materia de normas (sobre construcciones, gestión ganadera o forestal, lucha contra plagas y enfermedades, etc.). El paisaje deviene algo amenazador cuando lo evocan los habitantes de las ciudades.

Porque desde la ciudad se habla constantemente del paisaje que se pierde, como se estropea el campo, pero pocas veces, del paisaje que desde el campo los agricultores están perdiendo, cuando miran hacia el horizonte y ven crecer desmesuradamente pueblos y ciudades y todo tipo de infraestructuras. La ciudad también les "roba" su paisaje.

El dictamen sobre agricultura periurbana aprobado por el Comité Económico y Social Europeo afirma textualmente que “... a los problemas tradicionales de los espacios agrarios periurbanos se ha de añadir uno de más reciente aparición, que justifica la defensa de los espacios libres alrededor de las ciudades, pero sin actividad agrícola. Es, en definitiva, una visión del territorio como "parque temático", donde todo resulta artificializado, descontextualizado e impersonal, justificado bajo determinados criterios estéticos, apoyados falsa y únicamente en la preservación de la biodiversidad, o en una concepción del paisaje que intenta marginar o folklorizar la actividad agraria". ${ }^{2}$

\footnotetext{
2 CES 1209-004_ac_es.doc. Dictamen sobre "agricultura periurbana" aprobado en sesión plenaria del CESE el 16 de septiembre de 2004.
}

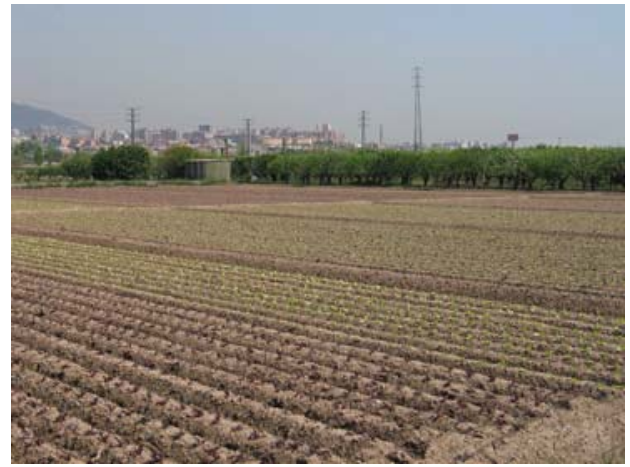

El campo entendido como un espacio productivo 
El profesor de la Escuela de Arquitectura de Paris-la-Villette, Alain Roger, en su libro "Breve tratado del paisaje", ${ }^{3}$ destaca la dicotomía entre los habitantes de las ciudades y los agricultores en el momento de observar un paisaje agrario. Lo hace citando este diálogo, "Es bonito, este prado", y Fage hijo contesta: "Si, da mil gavillas de heno". ${ }^{4}$ Para el habitante de la ciudad el campo "es bonito", para el agricultor el campo "es productivo", dos formas de ver y comprender un mismo paisaje. Dos maneras que pudiendo ser complementarias, muchas veces resultan divergentes y por ende conflictivas.

Por esta razón es preciso que tanto uno como otro hagan una "inmersión territorial", es decir, que el que asocia el campo a belleza intente adentrarse en el mundo de la producción, comprender el significado de cada actuación agronómica, buscar también la belleza en la propia actividad agraria, "simbiotizarse" con la tierra. Pero también es necesario que el campesino cambie de escala, se aleje de "su" campo, busque perspectivas más amplias, valore el conjunto e intente comprender la armonía de colores, de texturas, de formas. Sólo así es posible un entendimiento entre los ciudadanos "observadores del paisaje" y los agricultores "constructores de paisaje". El utilitarismo no debe fagocitar la belleza, pero tampoco ésta puede paralizar y momificar los territorios para que respondan a imágenes más o menos estereotipadas. Es necesario que ambas partes tomen conciencia de su realidad, y que lo hagan, lo hagamos, de forma crítica y comprometida con el cambio (concientizarse) ${ }^{5}$

Desde el Parque Agrario se intenta hacer la correspondiente "inmersión territorial", buscando el equilibrio entre preservar los valores de que dispone (sus recursos, agua, suelo, flora, fauna; los valores ecológicos y culturales, el patrimonio arquitectónico y genético; el paisaje; las tradiciones; la estructura

\footnotetext{
${ }^{3}$ ROGER, Alain (2000) p.30 y 31.

4 DE LA SOUDIÉRE, Martín (1985) p.21 y 23.

5 Según el pedagogo Paolo Freire (Recife, 1921-San Pablo, 1997) "concientizar" es tomar conciencia de la realidad de forma crítica y comprometida. No es suficiente limitarse a hacer una lectura del territorio e incluso analizar su contexto, es preciso tomar postura y actuar en conciencia.
}

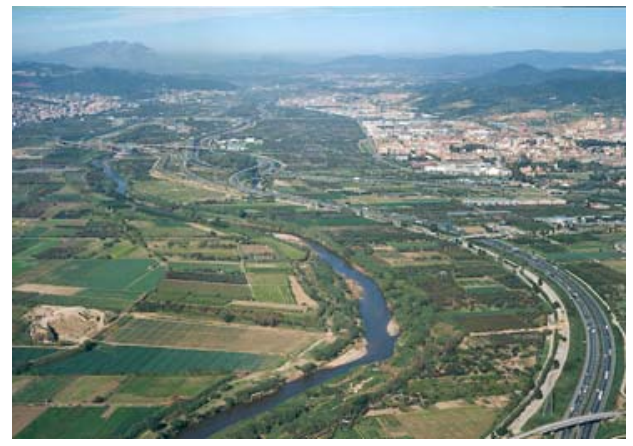

Vista aérea del Delta de río Llobregat

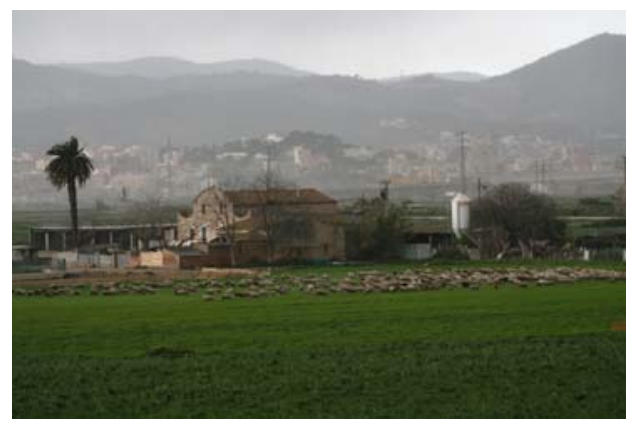

El paisaje del parque agrario. 
agraria) y desarrollar las funciones de dicho territorio, las económicas, propias de la actividad agraria; las ambientales al actuar como pulmón del entorno urbano, de amortiguador de ruidos, de espacio de recarga freática; y las sociales, al encontrar aquí la sociedad un lugar para el ocio, para la educación ambiental o para la investigación. Desde el Parque Agrario se intenta ser conservador en preservar sus valores y progresista en desarrollar sus funciones. El punto de confluencia entre valores y funciones es lo que denominamos la "sostenibilidad de un territorio".

¿En qué se concreta esta voluntad de confluir hacia la sostenibilidad?

En no renunciar a nada, si todo viene dado no solo a partir de la información, sino del razonamiento fundamental, de la reflexión; en crear las bases para que los agricultores entiendan los procesos y por tanto interioricen la necesidad de desarrollar habilidades para reinventar y/o recuperar nuevas formas de trabajar, más respetuosas con el medio agrario y natural.

Llegados a este punto conviene recordar que la agricultura es una actividad dinámica y cambiante, donde aparecen plagas y enfermedades, donde los precios del mercado son variables, donde la climatología evoluciona a lo largo del año y donde las políticas de las administraciones inciden sobre la actividad agraria. Por todo esto necesitamos comprender que las técnicas o las buenas intenciones pueden resultar obsoletas. De aquí la necesidad de la inmersión territorial y de enseñar procesos, más que almacenar conocimientos o imágenes preestablecidas.

En los documentos fundamentales para entender el Parque Agrario, el Plan de Gestión y Desarrollo (PGD) ${ }^{6}$ y el Plan Especial de preservación y mejora ${ }^{7}$; así

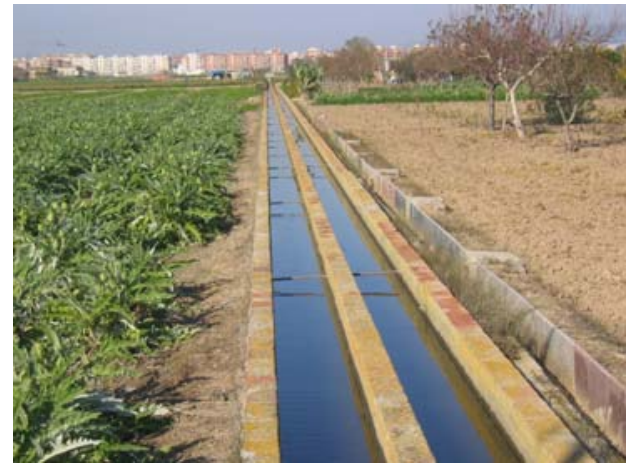

La red de canales del parque es un valor importante a conservar dentro del agrosistema agrario.

\footnotetext{
6 En el año 1998 se elabora el Plan de Gestión y Desarrollo, documento resultado de amplios debates entre los socios promotores del Parque Agrario del Baix Llobregat. Sin embargo no es hasta el 5 de junio de 2002 cuando el Consejo Plenario del Parque Agrario del Baix Llobregat aprueba definitivamente este plan introduciendo tan sólo pequeñas modificaciones, fruto de la experiencia adquirida durante estos años de gestión efectiva.

7 La Comisión Territorial de Urbanismo de Barcelona, en sesión del 16 de junio de 2004, da conformidad al texto refundido del Plan Especial y publica sus Normas Urbanísticas en el Diario Oficial de la Generalitat de Cataluña, a efectos de su ejecutividad inmediata. La
} 
como en los estudios previos, y muy especialmente en los realizados en la fase de redacción del Plan Especial, ${ }^{8}$ se interpreta el territorio del Parque Agrario desde una perspectiva integral, como un "agrosistema", donde tan importante es mantener una red de caminos y de riego eficientes, como que los recursos no dañen y tengan calidad, o evitar construcciones ajenas a la actividad agraria y regular su uso social para hacerlo compatible con la actividad agraria. El Parque Agrario no es la suma de individualidades patrimoniales, sino un todo, que como ecosistema agrario quiere ser armónico en su conjunto.

Cinco acciones concretas sirven para ejemplificar lo que se ha comentado: "els estanyats de Cal Roc"; el fomento de la producción integrada y la producción ecológica; el Arboterum de Can Comas; el programa "el ecosistema agrario" y la recuperación del patrimonio arquitectónico.

1. El Parque Agrario convive con espacios que disfrutan de especial protección por sus valores naturales. Uno de ellos es "L'Estany de la Ricarda", 9 en el municipio de El Prat de Llobregat, lindante con la finca de Cal Roc, propiedad del Hospital de la Santa Creu y Sant Pau de Barcelona y cultivada por agricultores arrendatarios. Desde hace tiempo el Consorcio del Parque Agrario colabora con la "Associació de Pagesos de Cal Roc", para mantener inundadas varias parcelas durante unos meses, en dos épocas del año. La finalidad es que pueda acoger diversas especies de aves y colaborar así en mantener la riqueza ornitológica de "La Ricarda" y del delta del Llobregat en su conjunto, al tiempo que se recupera una antigua tradición agronómica propia del delta, como son los "estanyats". ${ }^{10}$

normativa es finalmente publicada en el DOCG número 4216, el 10 de septiembre de 2004.

8 CCRS arquitectos (1997) y (2001)

9 Reserva natural parcial del Delta del Llobregat (Decreto 226/1987), Espacio de interés natural del Delta del Llobregat (Decreto 328/1992) y Zona de especial protección de aves (ZEPA) del Delta del Llobregat (Directiva 79/409/CEE).

${ }^{10}$ Estanyat: inundación temporal de los campos de cultivo como medida agronómica. 
- 2. El Consorcio, recogiendo lo que se propone en el Plan de Gestión y Desarrollo, está llevando a cabo una campaña de fomento de la producción integrada y ecológica, superando los métodos de producción convencional, apoyando la labor que están haciendo las tres asociaciones de defensa vegetal del Baix Llobregat. Se trata de producir alimentos con métodos más respetuosos con la salud humana y con el medio ambiente, con el objetivo de obtener productos de calidad, optimizar los métodos de cultivo y disminuir los residuos. Esto comporta recuperar y adaptar antiguas pautas de gestión agronómica donde nada es un problema en sí mismo, sino que hay causas que los provocan y es aquí donde es necesario incidir. El respeto a la flora, a la fauna o el uso del suelo, son fundamentales y por tanto de gran repercusión sobre el paisaje.

- $\quad$ 3. Si una producción ha caracterizado el Baix Llobregat han sido sus frutas, con especies y variedades muy apreciadas por los mercados. Pero la aparición de variedades más productivas ha ido arrinconando las más tradicionales y amenazando con ello un patrimonio genético importante. Desde el Consorcio del Parque Agrario, conscientes de la pérdida de este patrimonio, se pone en marcha en el año 2000 , un programa de recuperación de estas variedades tradicionales con el soporte del programa Life - Medio Ambiente europeo y con la ayuda técnica de la Generalitat de Catalunya. Para ello se ubica en la masía de Can Comas un "Centro de información y servicios del Parque Agrario" y un arboterum con 62 variedades de 8 especies de frutales. Se trata de salvaguardar un material genético que está en peligro inminente de desaparecer por las dificultades de subsistir frente a las variedades modernas.

En esta línea de soporte al patrimonio genético, desde el Parque Agrario se apoyan también los esfuerzos que desde la Asociación de Criadores de Pollo y Capón de la raza Prat se están haciendo para recuperar esta raza de pollos conocidos como de "pata azul" (que

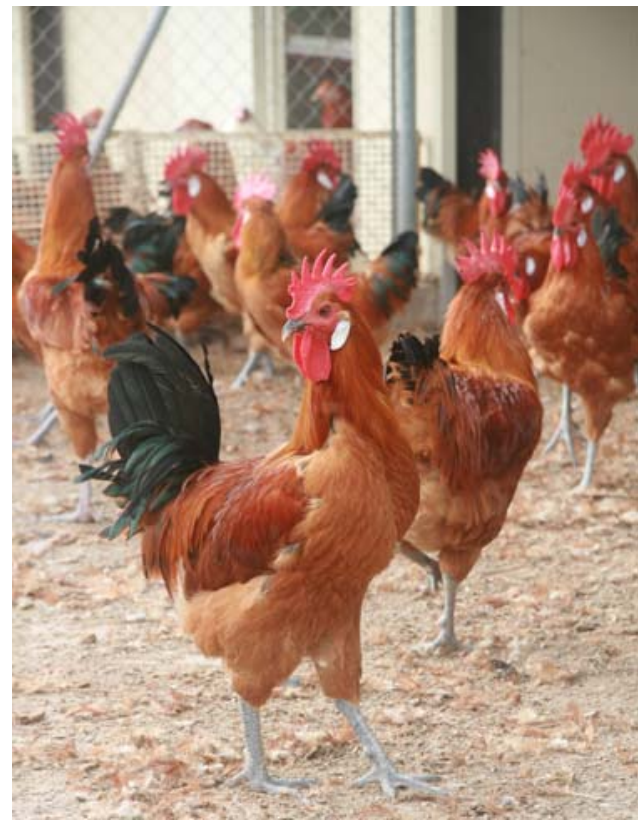

Pollos de la raza Prat, uno de los valores del parque agrario

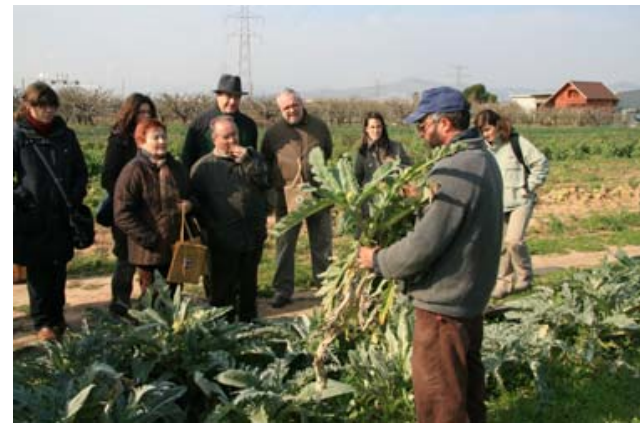

Los programas pedagógicos son una alternativa para fomentar el desarrollo del parque 
ostenta un reconocimiento europeo con la Indicación Geográfica de Producción).

- 4. Este patrimonio paisajístico y cultural que ofrece el Parque Agrario en medio de un entorno urbano, es todavía un gran desconocido. Es necesario ponerlo en valor y nada mejor que hacer realidad el dicho "se quiere lo que se conoce". De aquí la voluntad de impulsar un programa pedagógico denominado "el ecosistema agrario", dirigido a escolares del último curso de primaria de las escuelas de 14 municipios que forman parte del Consorcio del Parque Agrario. Se trata de un programa con material de soporte para los profesores, formado por un vídeo y un cuaderno explicativo, y para los alumnos, con un cuaderno de campo y la realización de observaciones y prácticas "in situ" en la masía de Can Comas, con el apoyo de monitores especializados y de un agricultor-monitor. Actividades que, además de dar a conocer la realidad agraria del delta y el valle del río Llobregat, no desaprovechan su proximidad a Can Comas para profundizar sobre el río, razón explicativa, entre otras, de la existencia del delta, de la amplia red de riego para los cultivos y de la propia actividad agraria.

- 5. Al igual que las anteriores actuaciones, el Plan de gestión y desarrollo recoge entre sus medidas prioritarias la de "dar soporte a la rehabilitación de las construcciones tradicionales existentes en el Parque Agrario". Desde el Consorcio se ha hecho el esfuerzo de recuperar, como Centro de Información y Servicios del Parque Agrario, una antigua masía situada en el término municipal de El Prat de Llobregat conocida como Can Comas. Esta masía fue edificada en 1878 en sustitución a otra datada entre los siglos XVI y XVII. Cabe precisar, que aún no teniendo un programa específico que lo ampare, se han rehabilitado o están en fase de rehabilitación otras masías históricas como la de Mas Pineda de Sant Boi de Llobregat (construida en 1909 y declarada bien cultural de interés local) y la de

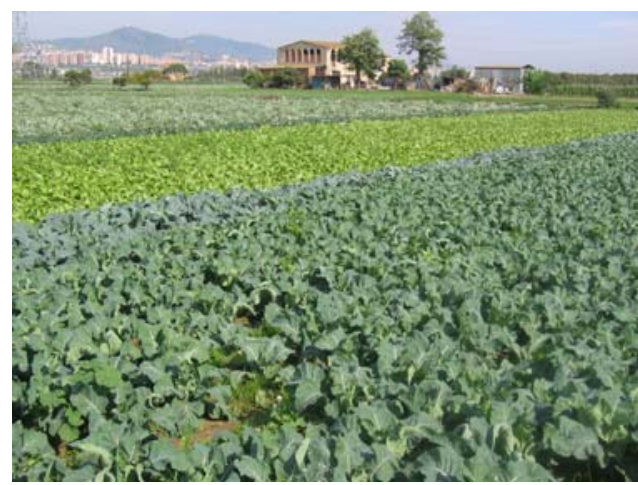

Imagen del parque agrario. Se destaca la presencia de un importante número de piezas de valor patrimonial dentro del entorno agrario.

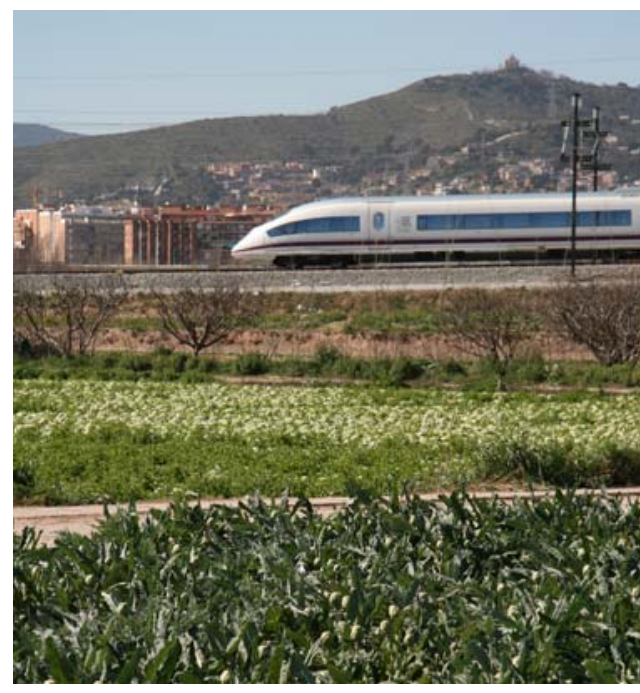

El paisaje agrario debe convivir con las nuevas infraestructuras que transitan por el ámbito del parque 
Cal Misses en El Prat de Llobregat (levantada en el siglo XIX y reformada en 1886).

El Parque Agrario del Baix Llobregat es una pieza más, de las muchas que configuran el eje del río Llobregat. Considerado en su conjunto destaca la notable concentración de patrimonio formado por ricos y diversos paisajes culturales donde el agua es el elemento aglutinador. "Los márgenes del que hemos denominado "el río más trabajador de Europa" albergan una densidad patrimonial poco común. Sus aguas han sido aprovechadas al máximo con canales, acequias, molinos, fábricas y colonias. La enorme coherencia que ofrece el curso del río como eje patrimonial proviene, precisamente, de su aprovechamiento integral". ${ }^{11}$

La preservación y dinamización del patrimonio paisajístico y cultural es muy necesaria, ya que el delta y el valle del río Llobregat se han visto constantemente amenazados por infraestructuras de todo tipo y por aquellos que la dañan, y que después tienen la necesidad de reinventar el paisaje, que difícilmente tendrá un carácter cultural, sino más bien un carácter "pseudoreligioso", donde las actuaciones no son otra cosa que la pretensión de "reconciliarse" con la naturaleza dañada por razones, dicen, "de interés general".

El proyecto del Parque Agrario ha tenido claro desde sus comienzos que su objetivo fundamental “... de evitar su incorporación al proceso urbano, garantizando así que se pueda llevar a cabo, con cierta estabilidad, una actividad agraria profesional", en ningún caso puede olvidarse de añadir la preservación del medio y el uso social que este territorio reclama y debe tener, ya que actividad productiva, el medio y su uso social configuran el verdadero paisaje cultural del delta y del valle del Llobregat.

${ }^{11}$ SABATÉ, Joaquín (2001) p. 31 


\section{BIBLIOGRAFÍA}

CCRS arquitectos (1997) Avance del Plan especial del Parque Agrario del Baix Llobregat. Barcelona

CCRS arquitectos (2001) Propuesta del Plan especial del Parque Agrario del Baix Llobregat. Barcelona

DE LA SOUDIÉRE, Martín (1985) "Regards sur un terroir et ailleurs. Les paysages à l'ombre des terroirs", Paysage et amenegement.

ROGER, Alain (2000) "Breve tratado del paisaje" Ediciones La Campana. Barcelona

SABATÉ, Joaquín (2001) "Dos visiones para el corredor del río Llobregat" en "Proyectando el eje del Llobregat. Paisaje cultural y desarrollo regional." Universidad Politécnica de Catalunya y Massachussets Institute of Technology. Barcelona. 